The first stage of the building includes : ward accommodation for 54 patients, together with very ample day space and facilities, the Drapers' Wing for 16 elderly people, some staff rooms, and the outpatients' clinic. The ward block will finally accommodate 75 patients; the regional hospital board will have contractual arrangements for 40 of the original 54 beds, and these will therefore be free to patients. Money will be raised in various ways for the other patients and residents.
The hospice illustrates very forcibly the important and valuable part that voluntary institutions can still play in a country whose medical needs are almost entirely met by a State service. The practical realization of the vision for St. Christopher's demonstrates also how by hard work and dedication very large voluntary projects indeed can start from the smallest beginnings and come successfully to fruition even in these supposedly complacent days of the Welfare State.

\title{
Radio Communication and the Emergency Department
}

\author{
M. H. HALL,* M.R.C.S., L.R.C.P. ; R. S. GARDEN, † M.B., M.CH.ORTH., F.R.C.S.ED.
}

Brit. med. F., 1967, 3, 170-171

Several years ago it was decided to investigate the use of radio communication between the Emergency Department and the ambulances serving the Preston Royal Infirmary (Garden, 1962). The telephone line already existing between Lancashire County Council ambulance headquarters and the hospital was used to complete the radio link, but technical problems arising from the length of the land lines caused some delay in the early stages. Improvements made by the radio department staff of the Lancashire County Constabulary, however, enabled the ambulance headquarters operator to monitor the signal and switch from transmit to receive as required. At the hospital the telephone line terminating in the ambulance officers' room was extended into the Emergency and Accident Department (Fig. E). An ordinary bell-push beside the telephone in the ambulance officers' room was installed to ring a warning bell in the emergency department when an ambulance attendant wished to communicate by radio with the medical officer on duty during the day (Fig. A). At other times an indicator relay worked by the telephone circuit was used as a warning device (Fig. B).

This experimental arrangement proved to be of immediate value in alerting the hospital staff of the impending arrival of seriously ill or injured patients, and in maintaining contact between the hospital and the flying squad dealing with motorists or workmen trapped as a result of road or industrial accidents.

The Emergency and Accident Department is extremely cramped ; over 30,000 new patients are treated annually within a total floor area of only 956 square feet. During a large part of the day there is little unused space, but the information that a seriously injured patient is on his way to hospital allows time for room to be made available and resuscitation equipment to be set out. If several patients are expected, confusion and delay in treatment are avoided by calling extra help to the department before the patients reach the hospital.

It soon became apparent that if advantage was to be taken of this early warning it was essential to set out full resuscitation equipment before each patient arrived. This required the design of new types of equipment and the development of fresh methods of instrument storage to overcome the inherent diffculties under which the department is required to work.

Because the results of this initial experiment were so successful, radio-link facilities were extended to the Borough ambulance vehicles, using a remote-control unit installed in the Emergency Department (Fig. D). This unit was connected to the tieline between the hospital and the Borough ambulance headquarters (Fig. F), the telephones being disconnected from the tie-line by a switch (Fig. C) when the radio link was in operation. This arrangement proved easier to operate than the County system, because the send-receive switch was incor- porated in the handset of the control unit. Warning devices similar to those in use for the County system were installed for use during the appropriate hours (Fig. $\mathrm{A}^{1}, \mathrm{~B}^{1}$ ).

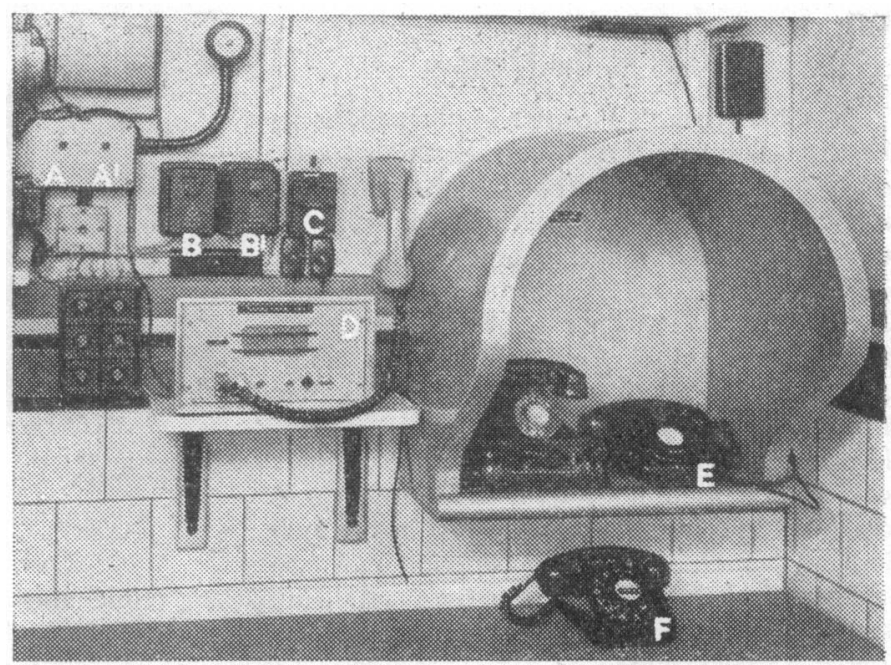

The radio-link installation. A, County, and $\mathrm{A}^{1}$, Borough daytime warning bells. $B$, County, and $B^{1}$, Borough nighttime indicator relays. $C$, ing bells. B, County, and Radio/telephone switch for Borough system. D, Remote control unit for Borough transmitter. E, Tie-line telephone to County ambulance
headquarters. F, Tie-line telephon: to Borough ambulance headquarters.

To ensure that all members of the staff are able to use the equipment a short test transmission is made every morning. This has proved helpful in overcoming the strangeness felt by most people using radio communication for the first time.

\section{Results}

One of the most gratifying and highly welcome by-products of the early warning system has been the unexpected competition that has arisen between the ambulance personnel and the departmental staff to ensure immediate attention for seriously injured patients.

It has clearly emerged that the avoidance of even a minute's delay in starting resuscitation can preserve lives which even a few years ago would have been lost. As an example, 97 patients suffering from severe multiple injuries have been treated in the department during the past three years. Of these patients 68 had sustained crush injuries of the chest and 32 showed para-

* Senior Accident Officer, Preston Royal Infirmary.

t Consultant Orthopaedic Surgeon, Preston Royal Infirmary ; Lecturer in Clinical Orthopaedic Surgery, University of Liverpool. 
doxical respiration. The overall mortality was $20 \%$, and many patients who were in extremis on arrival would certainly not have survived if the department had been inadequately equipped or unprepared for the immediate relief of respiratory embarrassment.

\section{Discussion}

Apart from its value in the management of trauma, the radio link enables advice to be given direct to the ambulance personnel. This facility is greatly valued, as they no longer feel cut off from medical aid when faced with difficult problems, especially during the transport of seriously ill or injured patients to the Accident and Emergency Department. On occasion it is tempting to shorten the journey by taking the patient to the nearest hospital, but this is not always in the best interests of the patient, and radio contact with the accident centre can help to relieve the anxiety of the ambulance personnel in these circumstances.

Abuse of the flying squad is prevented by avoiding call-out when the information received over the radio link makes it clear that little or no benefit can be expected.

The radio link enables the most efficient use to be made of the available nursing staff during the night, because the senior nurses can continue their normal duties in other departments and need not be summoned to the emergency unit until the patients are expected to arrive.

When the emergency team is summoned to an accident messages can be sent back to the hospital with information about the patient's condition and the estimated time when he is likely to be brought to the hospital (Hall, 1965).

The emergency team was called out at 4 a.m. to deal with a lorry driver trapped in the cab of his vehicle after a motorway accident. A message was sent to the hospital stating that his release would take a long time.

Subsequent messages asked for two pints (1.14 l.) of Group $\mathrm{O} R \mathrm{R}$-negative blood to be sent to the scene of the accident. A transfusion was begun while the driver was still trapped, and a short general anaesthetic was needed before he could be extricated at 6.30 a.m. A message was then sent with the information that the patient would reach the hospital in 30 minutes' time.

Because the patient was receiving a blood transfusion, and because his fractures were immobilized, a slow and steady journey to the hospital was possible. There was no need for haste, and when he arrived in the emergency department his condition was appreciably better than it had been when he left the scene of the accident.

\section{Future Developments}

The radio link at Preston Royal Infirmary operates over the normal telephone cables, but this is not necessarily the best arrangement under every circumstance. The use of a radio transmitter under the department's control would provide additional facilities, although tie-lines would still be needed to avoid constant monitoring by the hospital staff (Collins, 1966). A transmitter with several channels would allow the department to contact direct not only the ambulances but also the police and fire services. This would be helpful on many occasions, and discussions are now being held with a view to the acquisition of suitable apparatus. Adjacent ambulance services, using different radio frequencies, could then contact the hospital during the transference of, for example, neurosurgical patients coming for treatment from hospitals some distance away. Should the condition of these patients cause anxiety, direct contact with the receiving hospital would permit advice or active help to be given during the journey. Unfortunately this is not generally practical at the present time because of the widely differing frequencies and types of modulation used in the radio installations of various ambulance authorities. It is hoped, however, that the committee now considering the equipment of the ambulance services will make recommendations which will enable a standard type of communication set to be used in emergency departments throughout the country.

Experiments are now being undertaken to transmit electrocardiographic information by radio link from the ambulance. If this proves to be practicable it will allow monitoring of the cardiac state of patients with severe injuries or collapse after coronary thrombosis, and by giving advice to ambulance personnel the survival rate, especially from coronary infarction in the younger age groups, might possibly be increased.

Messages from a mountain rescue team several miles away have been relayed directly into the emergency department, and there is no obstacle now to the provision of similar facilities for air-sea helicopters or other rescue services. Indeed, it is only by enabling all rescue services to collaborate at an early stage that significant advances will be made in the treatment of casualties before they reach a hospital. With this in mind, it would seem logical that the allocation of a common national rescue radio-frequency should be considered by the General Post Office.

Little thought has been given in the past to the care of patients before they reach hospital, but the attention of the ambulance services has now been drawn to this deficiency (Working Party Report, 1966). Emergency departments should likewise appreciate the expanding part they have to play in this direction. Although the next ten years will doubtless see an expansion of the facilities for the early management of the seriously injured greater than has ever occurred before, the ideal of medical help for the patient from the moment of injury will remain a physical impossibility. An adequate communication network, however, will at least ensure that medical advice is available at the earliest possible moment.

We wish to acknowledge the enthusiastic help we have received from the staff of the Preston Borough and Lancashire County Council ambulance services and the radio department of the Lancashire County Constabulary.

\section{REFERENCES}

Collins, J. (1966). Brit. med. F., 2, 578.

Garden, R. S. (1962). In Modern Trends in Orthopaedics (Fracture Treatment), edited by J. M. P. Clark, 3, 59. London.

Hall, M. H. (1965). Lancet, 1, 904.

Working Party Report on Ambulance Training and Equipment (1966). Part I, Training. H.M. Stationery Office, London. 